\title{
Predictors of Outcome of Living Donor Liver Transplantation for Hepatocellular Carcinoma
}

\author{
Hazem Mohamed Zakaria ${ }^{1}$ - Ahmed N. Sallam ${ }^{1}$ - Islam I. Ayoub ${ }^{1} \cdot$ Sherif M. Saleh $^{1}$ • \\ Doha Maher $^{2}$ - Hazem Omar ${ }^{3}$ - Mohamed Abou-Shady ${ }^{1}$ Ibrahim A. Salama ${ }^{1}$. \\ El-Sayed A. Soliman ${ }^{1} \cdot$ Khaled Abou El-Ella $^{1} \cdot$ Tarek M. Ibrahim $^{1} \cdot$ Essam M. Hammad $^{1}$
}

Received: 3 June 2015 / Accepted: 14 March 2016 / Published online: 7 April 2016

(C) Association of Surgeons of India 2016

\begin{abstract}
The aim of this work is to study the different factors that affect the outcome of living donor liver transplantation for patients with hepatocellular carcinoma (HCC). Between April 2003 to November 2014, 62 patients with liver cirrhosis and HCC underwent living donor liver transplantation (LDLT) in the National Liver Institute, Menoufia University, Egypt. The preoperative, operative, and postoperative data were analyzed. After studying the pathology of explanted liver; 44 (71\%) patients were within the Milan criteria, and 18 (29\%) patients were beyond Milan; 13 (21.7\%) of patients beyond the Milan criteria were also beyond the University of California San Francisco criteria (UCSF) criteria. Preoperative ablative therapy for HCC was done in 22 patients (35.5\%), four patients had complete ablation with no residual tumor tissues. Microvascular invasion was present in ten patients $(16 \%)$ in histopathological study. Seven (11.3\%) patients had recurrent HCC post transplantation. The 1, 3, 5 years total survival was 88.7, 77.9, 67.2\%, respectively, while the tumor-free survival was $87.3,82.5,77.6 \%$, respectively. Expansion of selection criteria beyond Milan and UCSF had no increased risk effect on recurrence of HCC but had less survival rate than patients
\end{abstract}

Hazem Mohamed Zakaria

hazemlasheenn@yahoo.com

1 Department of Hepato-pancreao-biliary \& Liver Transplantation Surgery, National Liver Institute, Menoufia University, 32511 Shebin El-koom, Menoufia, Egypt

2 Department of Pathology, National Liver Institute, Menoufia University, 32511 Shebin El-koom, Menoufia, Egypt

3 Department of Diagnostic and Interventional Radiology, National Liver Institute, Menoufia University, 32511 Shebin El-koom, Menoufia, Egypt within the Milan criteria. Microvascular invasion was an independent risk factor for tumor recurrence.

Keywords Hepatocellular carcinoma $\cdot$ Living donor liver transplantation $\cdot$ Milan criteria $\cdot$ Survival $\cdot$ Recurrence

\section{Introduction}

Hepatocellular carcinoma (HCC) is the most common primary hepatic malignancy, representing more than $90 \%$ of primary liver neoplasms. Its incidence is high in Africa and Asia and has substantially increased worldwide during the past three decades. The majority of HCC (80-90\%) are associated with underlying liver disease related to post-hepatitis cirrhosis or alcohol abuse [1].

Liver transplantation (LT) is in theory the optimal treatment for cirrhotic patients with HCC, due to the advantage of removing the tumor, and preventing the possibility of metachronous lesions on underlying cirrhosis and restoring normal liver function. However, high recurrence rates and poor outcomes were recorded from the first era of LT. These poor results were mostly related to unrestrictive selection criteria, inclusion of patients with macroscopic vascular invasion, and lymph node involvement $[2,3]$.

The aim of this work is to study the different preoperative, operative, and postoperative factors that may affect the survival and recurrence of the tumor in HCC patients after LDLT.

\section{Patients and Methods}

This is a retrospective analysis of liver transplanted patients for HCC in the National Liver Institute, Menoufia University, Egypt, in the period from April 2003 to November 2014. During this 
period, 234 patients underwent LDLT. Hepatocellular carcinoma was the indication of LDLT in $62(26.4 \%)$ patients.

Preoperative, operative, and postoperative data were studied and statistically analyzed for its relation with the survival and recurrence of $\mathrm{HCC}$.

The selection criteria for patients were; the Milan criteria ( single tumor $\leq 5 \mathrm{~cm}$; or $\leq 3$ tumors each $\leq 3 \mathrm{~cm}$; no vascular invasion and no distant metastases) [4], or the University of California San Francisco (UCSF) criteria(single tumor $\leq 6.5 \mathrm{~cm}$; or $\leq 3$ tumors, non $>4.5 \mathrm{~cm}$ and total diameter $\leq 8 \mathrm{~cm}$, no vascular invasion) [5], and beyond the Milan and UCSF criteria but total tumor volume (TTV) $<114 \mathrm{~cm}^{3}[6,7]$.

The volume of a tumor nodule is calculated by using the following mathematical equation: tumor volume $\left(\mathrm{cm}^{3}\right)=4$ / $3 \times 3.14 \times(\text { maximum radius of the tumor nodule in } \mathrm{cm})^{3}$ TTV $\left(\mathrm{cm}^{3}\right)=$ tumor volume of (tumor nodule $1+$ tumor nodule $2+\ldots+$ tumor nodule $\mathrm{N}$ ) [7].

Postoperative immunosuppressant regimen was methylprednisolone, Plus calcineurin inhibitors (CNI) like tacrolimus plus mycophenolate mofetil (MMF). If there are complications from tacrolimus, we shift to other CNI like cyclosporine or mammalian target of rapamycin (m-TOR) inhibitors, like everolimus or sirolimus.

Tacrolimus prescribed at an initial dose of $0.05-0.1 \mathrm{mg} / \mathrm{kg} /$ day divided every $12 \mathrm{~h}$, and adjusted over time to maintain levels of $10-15 \mathrm{ng} / \mathrm{mL}$ at $0-14$ days, $6-10 \mathrm{ng} / \mathrm{mL}$ at $14-$ 28 days, and 5-8 ng/mL thereafter. Cyclosporine was given at an oral dosage of $8-10 \mathrm{mg} / \mathrm{kg} / \mathrm{day}$, where blood trough levels were maintained between 150 and $250 \mathrm{ng} / \mathrm{ml}$ in the first 6 months and between 100 and $150 \mathrm{ng} / \mathrm{ml}$ thereafter. Sirolimus was given at an initial dose of $3 \mathrm{mg} / \mathrm{m}^{2}$ and adjusted over time to achieve blood trough levels of approximately $5-8 \mathrm{ng} / \mathrm{mL}$.

Mycophenolate mofetil was given at an oral dosage of 0.25 $1.0 \mathrm{~g}$ twice a day and it was stopped at the end of the 6th month post transplantation. The initial methylprednisolone dose is $500 \mathrm{mg}$ intraoperatively with a brief tapering over 6 days followed by $5-20 \mathrm{mg} / \mathrm{d}$ oral maintenance dose, with complete withdrawal at the end of the third month post transplant.

Duration of follow-up was from April 2003 to May 2015, with median period of follow up 49 months. Our protocol of follow-up of the recurrence was by abdominal ultrasound (US) every month, computerized tomography (CT) abdomen, and serial alpha fetoprotein (AFP) serum level every 3 months in the first year, and every 6 months in second and third year, then yearly. The perioperative mortality was considered the first 90 days post liver transplant, and cases with perioperative mortality were excluded during analysis of risk factors for recurrence.

\section{Statistical Analysis}

Data were collected and entered to the computer using SPSS (Statistical Package for Social Science), version 21.0 (SPSS
Inc., Chicago, IL, USA) program for statistical analysis. Chisquare test or Fisher's exact test were used to measure association between qualitative variables and survival and recurrence of HCC. The Student $t$ test and Mann-Whitney test were used to compare the relation of mean and SD of sets of quantitative distributed data. Multivariate analysis was done for factors affecting the recurrence of HCC and survival. Kaplan-Meier curve was plotted for analysis of total survival, and disease free survival. Log rank test was used to compare between two groups' survival. $p$ value was considered statistically significant when it was $<0.05$.

\section{Results}

Sixty-two patients underwent LDLT for liver cirrhosis with HCC; the mean age was 48.9 years old, and there were 59 male patients. The preoperative and operative data of the patients are listed in (Table 1).

According to preoperative CT image; 42 (67.7\%) patients were within the Milan criteria and $20(32.3 \%)$ patients were beyond Milan, and 10 (16.1\%) of them were also beyond the UCSF criteria. After studying the pathology of explanted liver; $44(71 \%)$ patients were within the Milan criteria, and $18(29 \%)$ patients were beyond Milan, $13(21.7 \%)$ of these patients that were beyond the Milan criteria were also beyond the UCSF criteria (as number of HCCs were $>3$ ) (Tables 1 and 2). We had three patients with recurrent HCC that were beyond UCSF criteria.

AFP was above $400 \mathrm{ng} / \mathrm{ml}$ in $8(12.9 \%)$ patients, and four of them AFP was $>1000 \mathrm{ng} / \mathrm{ml}$ (Table 1); all of these patients were poorly and moderately differentiated HCC in the histopathology, and the four patients with AFP >1000 ng/ml had recurrent HCC after 1 year of transplant.

Twenty-two (35.5\%) patients underwent ablation for HCC before preparation and scheduling for the transplant program. TACE $14(63.6 \%)$ patients, and RFA 6 (27.3\%) patients, were the most common ablative therapy to be used, with only two $(9.1 \%)$ patients who underwent alcohol injection. Four (18.2\%) of these patients that underwent locoregional therapy were well ablated in the histopathology of explanted liver with no residual tumor tissues (Table 2). Two patients with previous TACE had hepatic artery thrombosis (HAT) and one patient had portal vein thrombosis (PVT) in the early 3 months post LT.

Table 2 shows the histopathological data of explanted liver. Microvascular invasion was found in ten $(16.1 \%)$ patients. Only four cases with microvascular invasion had recurrent HCC, and six patients had postoperative mortality.

Most of the patients, $42(67.7 \%)$ continued on tacrolimus. We shifted to another CNI such as cyclosporine in seven patients $(11.3 \%)$ and shifted to m-TOR inhibitors such as sirolimus or everolimus in 13 patients $(21 \%)$. Five of these 
Table 1 Preoperative and operative data of HCC cases

\begin{tabular}{|c|c|}
\hline & HCC (62 patients) \\
\hline \multicolumn{2}{|l|}{ Viral markers } \\
\hline $\mathrm{HCV}$ & $59(95.2 \%)$ \\
\hline $\mathrm{HBV}$ & $2(3.2 \%)$ \\
\hline $\mathrm{HCV}$ and $\mathrm{HBV}$ & $1(1.6 \%)$ \\
\hline \multicolumn{2}{|l|}{ Child score } \\
\hline A & $8(12.9 \%)$ \\
\hline B & $31(50 \%)$ \\
\hline $\mathrm{C}$ & $23(37.1 \%)$ \\
\hline \multicolumn{2}{|l|}{ MELD score } \\
\hline Mean \pm SD & $14.2 \pm 4.4$ \\
\hline Range & $(7-34)$ \\
\hline MELD $<10$ & $6(9.7 \%)$ \\
\hline MELD 10-20 & $53(85.5 \%)$ \\
\hline MELD > 20 & $3(4.8 \%)$ \\
\hline \multicolumn{2}{|l|}{ Ascites } \\
\hline No & $20(32.2 \%)$ \\
\hline Mild & $13(21 \%)$ \\
\hline Moderate & $21(33.9 \%)$ \\
\hline Marked & $8(12.9 \%)$ \\
\hline \multicolumn{2}{|c|}{$\operatorname{AFP}(\mathrm{ng} / \mathrm{mL})($ normal $<12 \mathrm{ng} / \mathrm{mL})$} \\
\hline Mean \pm SD & $288.3 \pm 831.6$ \\
\hline Range & $(3.4-964)$ \\
\hline$\leq 20$ & $34(54.8 \%)$ \\
\hline$>20, \leq 400$ & $20(32.3 \%)$ \\
\hline$>400,<1000$ & $4(6.45 \%)$ \\
\hline$>1000$ & $4(6.45 \%)$ \\
\hline \multicolumn{2}{|l|}{ Milan criteria } \\
\hline Within & $42(67.7 \%)$ \\
\hline Beyond & $20(32.3 \%)$ \\
\hline \multicolumn{2}{|l|}{ UCSF criteria } \\
\hline Within & $52(83.9 \%)$ \\
\hline Beyond & $10(16.1 \%)$ \\
\hline \multicolumn{2}{|l|}{ GRWR } \\
\hline Mean \pm SD & $1 \pm 0.15$ \\
\hline Range & $(0.7-1.3)$ \\
\hline \multicolumn{2}{|l|}{ CIT (min) } \\
\hline Mean \pm SD & $61.6 \pm 24.1$ \\
\hline Range & $(25-120)$ \\
\hline \multicolumn{2}{|l|}{ WIT (min) } \\
\hline Mean $\pm \mathrm{SD}$ & $52.5 \pm 14.9$ \\
\hline Range & $(30-95)$ \\
\hline \multicolumn{2}{|l|}{ Oper time (h) } \\
\hline Mean $\pm \mathrm{SD}$ & $14.8 \pm 2.4$ \\
\hline Range & $(8-23)$ \\
\hline \multicolumn{2}{|l|}{ Blood (unit) } \\
\hline Mean $\pm \mathrm{SD}$ & $5.5 \pm 6.4$ \\
\hline Range & $(0-28)$ \\
\hline \multicolumn{2}{|l|}{ Plasma (unit) } \\
\hline Mean \pm SD & $7.2 \pm 10.1$ \\
\hline Range & $(0-30)$ \\
\hline
\end{tabular}

$H C C$ hepatocellular carcinoma, $H C V$ hepatitis $\mathrm{C}$ virus, $H B V$ hepatitis $\mathrm{B}$ virus, $M E L D$ model of end-stage liver disease, $S D$ standard deviation, $A F P$ alfa-fetoprotein, $n g$ nanogram, $m L$ milli Leter, GRWR graft recipient weight ratio, CIT cold ischemia time, WIT warm ischemia time, UCSF University of California San Francisco criteria

patients receiving tacrolimus had $\mathrm{HCC}$ recurrence and 12 patients had postoperative mortality.

Postoperative complications were mainly biliary complications in the form of bile leak in $16(25.8 \%)$ patients, and anastomotic biliary stricture in $5(8.1 \%)$ patients, most of it
Table 2 Pathological study of explanted liver

\begin{tabular}{|c|c|}
\hline Pathological study & No $(\%)$ \\
\hline FLs that underwent ablative therapy & 22 \\
\hline Well ablated & $4(18.2)$ \\
\hline Not well ablated & $18(81.8)$ \\
\hline Differentiation & $(n=58)$ \\
\hline Well differentiated & $20(34.5)$ \\
\hline Moderate differentiated & $36(62.1)$ \\
\hline Undifferentiated & $2(3.4)$ \\
\hline \multicolumn{2}{|l|}{ Capsule } \\
\hline Present & $11(17.7)$ \\
\hline Absent & $51(82.3)$ \\
\hline \multicolumn{2}{|l|}{ Microvascular invasion } \\
\hline Yes & $10(16.1)$ \\
\hline No & $52(83.9)$ \\
\hline \multicolumn{2}{|l|}{ Macrovascular invasion } \\
\hline Yes & $2(3.2)$ \\
\hline No & $60(96.8)$ \\
\hline Microscopic pattern of FLs & $(n=58)$ \\
\hline Trabecular & $19(32.8)$ \\
\hline Macrotrabecular & $12(20.7)$ \\
\hline Acinar & $5(8.6)$ \\
\hline Clear cell type & $3(5.2)$ \\
\hline Trabecular + acinar & $13(22.4)$ \\
\hline Macrotrabecular + acinar & $3(5.2)$ \\
\hline Macrotrabecular + solid & $2(3.4)$ \\
\hline Macrotrabecular + clear cell type & $1(1.7)$ \\
\hline \multicolumn{2}{|l|}{ Pathological Milan criteria } \\
\hline Within & $44(71)$ \\
\hline Beyond & $18(29)$ \\
\hline \multicolumn{2}{|l|}{ Pathological UCSF criteria } \\
\hline Within & $49(79)$ \\
\hline Beyond & $13(21)$ \\
\hline
\end{tabular}

FLs focal lesions, UCSF University of California San Francisco

controlled on conservative treatment, seven patients underwent endoscopic retrograde cholangiopancreaticography (ERCP), and two patients with biliary stricture underwent surgical correction by biliary enteric anastomosis. Vascular complications were in four patients in the form of HAT and PVT, and all of the patients with vascular complications had early first year mortality.

Seven $(11.3 \%)$ patients had HCC recurrence; HCC recurrence was seen mainly in the first 2 years with range of $11-$ 28 months postoperative. Three $(42.9 \%)$ of these patients had intrahepatic and extrahepatic recurrence, two $(28.6 \%)$ patients had only extrahepatic recurrence in the bones, and two (28.6\%) patients had only multiple hepatic recurrences (Table 3 ).

In the univariate analysis (Table 4) there was significant statistical relation between recurrence of HCC and AFP $>1000 \mathrm{ng} / \mathrm{ml}$ ( $p$ value $=0.01)$, low pathological grade $(p$ value $=0.03)$, and micovascular invasion $(p$ value $<0.01)$. In the multivariate analysis, only microvascular invasion was an independent risk factor for HCC recurrence after LDLT ( $p$ value $=0.01$ ). 


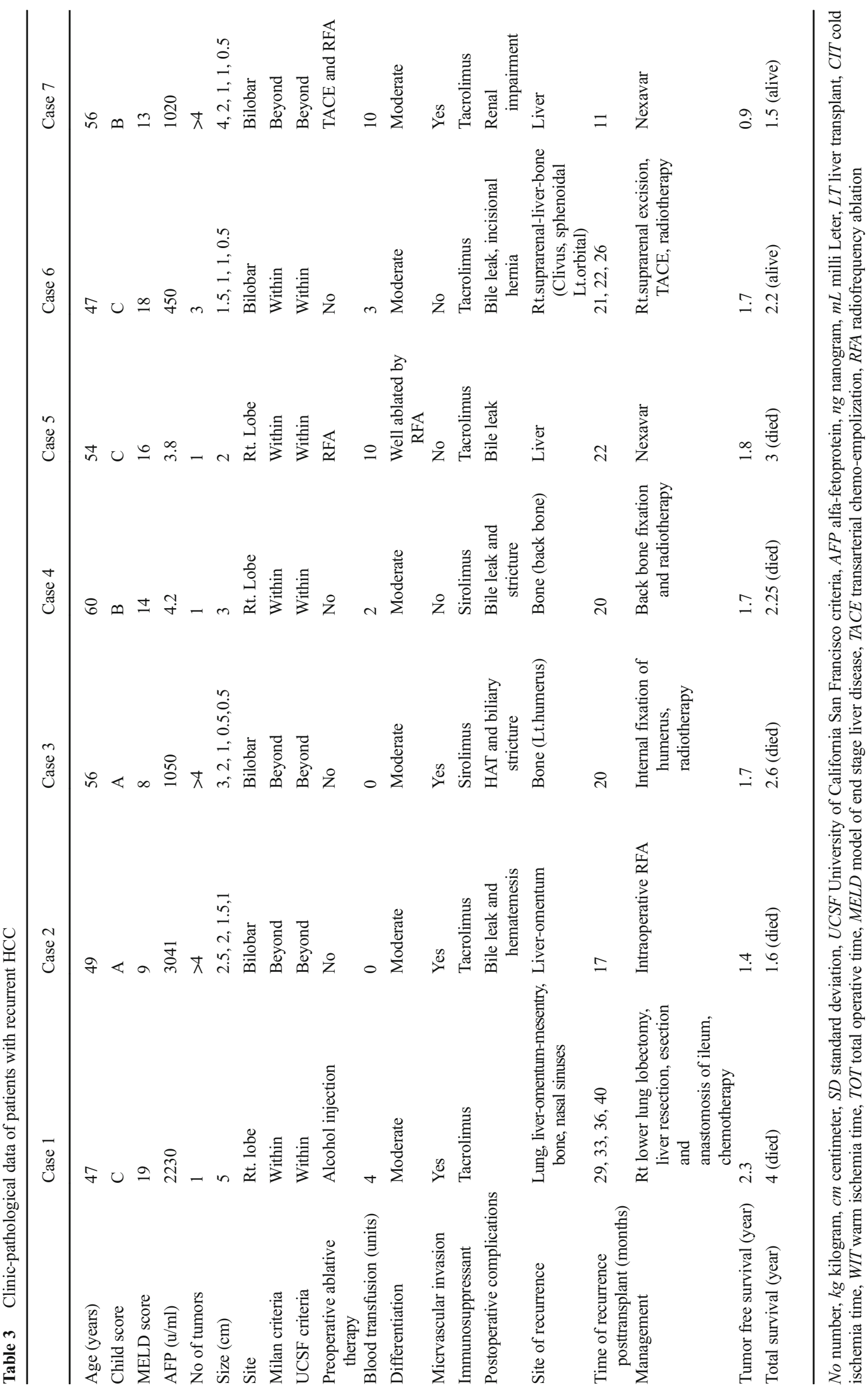


Table 4 Univariate analysis of factors affecting $\mathrm{HCC}$ recurrence (after exclusion of 90 days mortality)

\begin{tabular}{|c|c|c|c|}
\hline & HCC without recurrence $(n=50)$ & HCC with recurrence $(n=7)$ & $p$ value \\
\hline \multicolumn{4}{|l|}{ Age } \\
\hline Mean \pm SD & $48.6 \pm 6$ & $52.7 \pm 5.1$ & \multirow[t]{2}{*}{0.09} \\
\hline Range & $(40-59)$ & $(47-60)$ & \\
\hline \multicolumn{4}{|l|}{ Child score } \\
\hline $\mathrm{A}$ & $6(12 \%)$ & $2(28.6 \%)$ & \multirow[t]{3}{*}{0.43} \\
\hline $\mathrm{B}$ & $25(50 \%)$ & $2(28.6 \%)$ & \\
\hline $\mathrm{C}$ & $19(38 \%)$ & $3(42.8 \%)$ & \\
\hline \multicolumn{4}{|l|}{ MELD score } \\
\hline Mean $\pm \mathrm{SD}$ & $13.9 \pm 4.3$ & $13.9 \pm 4.2$ & \multirow[t]{2}{*}{0.99} \\
\hline Range & $(7-20)$ & $(8-19)$ & \\
\hline \multicolumn{4}{|c|}{$\operatorname{AFP}(\mathrm{ng} / \mathrm{mL})($ normal $<12 \mathrm{ng} / \mathrm{mL})$} \\
\hline Mean \pm SD & $164.5 \pm 611.4$ & $1361.8 \pm 1783.2$ & \multirow[t]{5}{*}{$<0.01$} \\
\hline Range & $(3.4-964)$ & $(3.8-4223)$ & \\
\hline$\leq 20$ & $24(48 \%)$ & $2(28.6 \%)$ & \\
\hline$>20, \leq 400$ & $20(37.8 \%)$ & 0 & \\
\hline$>400,<1000$ & $5(9.4 \%)$ & $1(14.3 \%)$ & \\
\hline$>1000$ & 0 & $4(57.1 \%)$ & 0.01 \\
\hline \multicolumn{4}{|l|}{ Blood transfusion (unit) } \\
\hline Mean $\pm \mathrm{SD}$ & $5 \pm 6$ & $4 \pm 4$ & \multirow[t]{2}{*}{0.81} \\
\hline Range & $(0-17)$ & $(0-10)$ & \\
\hline \multicolumn{4}{|l|}{ Pathological tumor grade } \\
\hline $\mathrm{I}, \mathrm{II}$ & $35(70 \%)$ & $3(42.85 \%)$ & \multirow[t]{2}{*}{0.03} \\
\hline III, IV & $15(30 \%)$ & $4(57.15 \%)$ & \\
\hline Unilobar & $34(68 \%)$ & $3(42.9 \%)$ & \multirow[t]{2}{*}{0.21} \\
\hline Bilobar & $16(32 \%)$ & $4(57.1 \%)$ & \\
\hline Tumor largest diameter $>3 \mathrm{~cm}$ & $10(20 \%)$ & $2(28.6 \%)$ & 0.63 \\
\hline Microvascular invasion & $4(8 \%)$ & $4(57.1 \%)$ & $<0.01$ \\
\hline CNI immunosuppressant & $35(70 \%)$ & $5(71.4 \%)$ & 1.0 \\
\hline \multicolumn{4}{|l|}{ Pathological Milan criteria } \\
\hline Within & $37(74 \%)$ & $4(57.1 \%)$ & \multirow[t]{2}{*}{0.39} \\
\hline Beyond & $13(26 \%)$ & $3(42.9 \%)$ & \\
\hline \multicolumn{4}{|l|}{ Pathological UCSF criteria } \\
\hline Within & $40(80 \%)$ & $4(57.1 \%)$ & \multirow[t]{2}{*}{0.33} \\
\hline Beyond & $10(20 \%)$ & $3(42.9 \%)$ & \\
\hline
\end{tabular}

Statistically significant values are shown in italic

$H C C$ hepatocellular carcinoma, $S D$ standard deviation, $H C V$ hepatitis $\mathrm{C}$ virus, $H B V$ hepatitis B virus, $M E L D$ model of end-stage liver disease, $S D$ standard deviation, $A F P$ alfa-fetoprotein, $n g$ nanogram, $m L$ milli Leter, $U C S F$ University of California San Francisco criteria, CNI calcineurin inhibitors
The 1-, 3-, and 5-year total survival for all patients was 88.7, 77.9, and 67.2\%, respectively (Fig. 1a). While the 1-, 3 -, and 5-year tumor-free survival (patients without recurrent HCC) was 87.3, 82.5, and 77.6\%, respectively, and the 1-, 3-, and 5-year survival in patients with recurrent HCC was 100 , 44.4 , and $0 \%$, respectively.

The total survival in patients within Milan (44 patients) at 1 , 3 , and 5 years was as follows: 93.2, 87, and $77.1 \%$, respectively, while the 1-, 3-, and 5-year survival in patients beyond Milan but within UCSF criteria (5 patients) was 60,30 , and $30 \%$, and the 1-, 3-, and 5-year survival in patients beyond UCSF criteria (13 patients) was 84.6, 66, and $53.3 \%$, respectively (Fig. 1b) ( $p$ value $=0.02$ ). Table 5 shows the causes and time of mortality.
In the univariate analysis of survival (Table 6), there was significant statistical relation between survival of patients with HCC and patients beyond pathological Milan $(p$ value $=0.03$ ), preoperative AFP $>1000 \mathrm{ng} / \mathrm{ml}$ ( $p$ val$\mathrm{ue}=0.05$ ), intraoperative massive blood transfusion ( $p$ value $=0.05)$, cold ischemia time $>1 \mathrm{~h}(p$ value $=0.04)$, moderate and poor tumor differentiation $(p$ value $=0.05)$, microvascular invasion ( $p$ value $=0.04)$, postoperative biliary and vascular complications ( $p$ value $=0.03$ ), and tumor recurrence $(p$ value $=0.01)$.

As regarding the multivariate analysis there was significant statistical relation between total survival of patients with $\mathrm{HCC}$, and selection criteria beyond Milan $(p$ value $=0.041)$ 

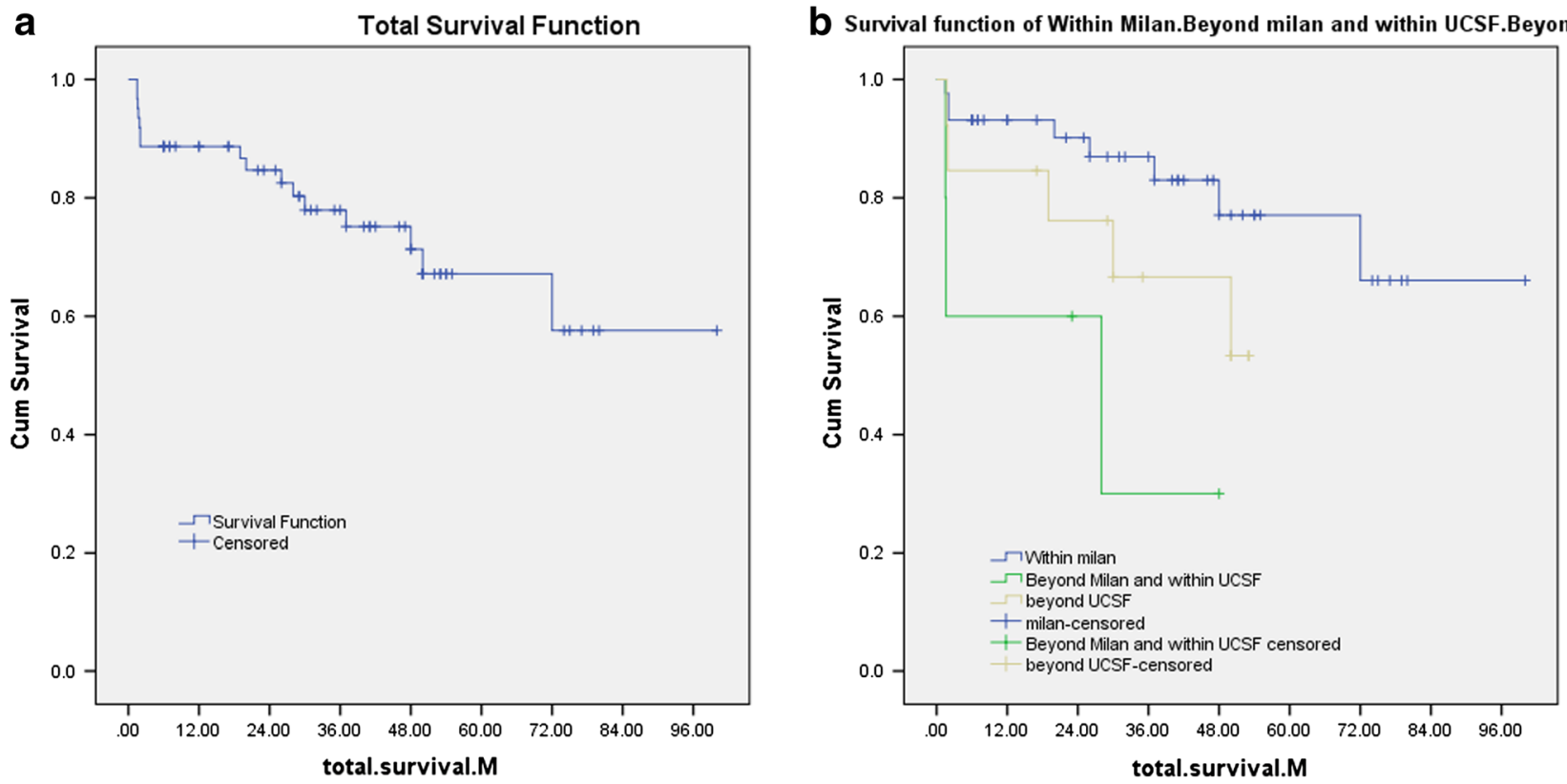

Fig. 1 Kaplan-Meier curve for survival. a Kaplan-Meier curve for total survival. b Kaplan-Meier curve for survival in patients within the Milan criteria, patients beyond Milan and within the UCSF criteria, and patients beyond the UCSF criteria

and beyond UCSF criteria ( $p$ value $=0.036$ ), microvascular invasion $(p$ value $=0.01)$, and recurrent $\operatorname{HCC}(p$ value $=0.05)$.

\section{Discussion}

Liver transplantation seems to be the most rationalized treatment for $\mathrm{HCC}$, because it both radically removes the primary tumor with all micrometastases that may be present and treats the cirrhosis [2].

Table 5 Causes and time of mortality

\begin{tabular}{lll}
\hline Cause of death & No (16/62) & $\begin{array}{l}\text { Time postoperative } \\
\text { (month) }\end{array}$ \\
\hline Recurrent HCC & 5 & $48,19,31,27,36$ \\
HAT, PVT & 2 & $1.9,2.2$ \\
HAT, sepsis & 1 & 2 \\
PVT & 1 & 3.5 \\
Chest infection and sepsis & 1 & 37 \\
Bile leak and sepsis & 1 & 0.9 \\
Renal impairment and heart failure & 1 & 15 \\
Pulmonary embolism & 1 & 5 \\
small for size & 1 & 2 \\
CMV infection and sepsis & 1 & 13 \\
TIPS and sepsis & 1 & 72
\end{tabular}

HAT hepatic artery thrombosis, PVT portal vein thrombosis, $C M V$ cytomegalo virus, TIPS trans jugular portosystemic shunt
By expanding the criteria from Milan to UCSF we had excess of $5(12 \%)$ patients that entered UCSF, with comparable good results. Yao et al., also reported that by expanding the Milan criteria for transplanting patients with HCC, an additional $23 \%$ of patients were transplanted with excellent outcome [5].

Our results regarding total survival and recurrence-free survival in patients within Milan and exceeding the Milan criteria were near to what were reported by Mazzaferro et al., in which the overall and recurrence-free survival rates at 4 years among the patients, who met the Milan criteria, were 85 and $92 \%$, respectively, whereas the rates in the 13 patients $(27 \%)$ whose tumors exceeded these limits were 50 and $59 \%$, respectively [4].

In 2001, Yao et al., from the UCSF were the first to challenge the parameters set by the Milan criteria. In their retrospective study, they had a 1- and 5-year overall survival of 90 and $75.2 \%$, respectively. It is also comparable to our results [5].

Concerning using total tumor volume (TTV) as a prognostic predictor was reported by Huo et al.; they suggested that TTV is a feasible alternative indicator of tumor burden for cancer staging, and accurately predict the outcome. A TTV of $50 \mathrm{~cm}^{3}$ is equivalent to a single tumor nodule with a diameter of $4.6 \mathrm{~cm}$. This cutoff is considered appropriate for clinical application because TTV $<50 \mathrm{~cm}^{3}$ is within the Milan criteria, suggesting the risk of tumor recurrence is very low after LT. But in our study, we did not use TTV for HCC staging before transplantation [7]. Also, Toso et al. stated that a study using the Organ Procurement and Transplant Network (OPTN) and the Scientific Registry of Transplant Recipients 
Table 6 Univariate analysis of factors affecting patient survival

\begin{tabular}{|c|c|c|c|c|}
\hline Characteristic & & $\begin{array}{l}\text { Number of deaths } \\
\text { per cases observed }\end{array}$ & $\%$ deaths & $p$ value \\
\hline \multirow[t]{2}{*}{ Gender } & Male & $2 / 3$ & 66.7 & 0.16 \\
\hline & Female & $14 / 59$ & 23.7 & \\
\hline \multirow[t]{2}{*}{ Comorbidities } & Yes & $7 / 28$ & 25 & 0.65 \\
\hline & No & $9 / 34$ & 26.5 & \\
\hline \multirow[t]{3}{*}{ Child Score } & A & $3 / 8$ & 37.5 & 0.53 \\
\hline & $\mathrm{B}$ & $9 / 31$ & 29 & \\
\hline & $\mathrm{C}$ & $4 / 23$ & 17.4 & \\
\hline \multirow[t]{2}{*}{ MELD score } & $\geq 10$ & $2 / 6$ & 33.3 & 0.16 \\
\hline & $<10$ & $14 / 56$ & 25 & \\
\hline \multirow[t]{2}{*}{ AFP (ng/ml) } & $>1000$ & $3 / 4$ & 75 & 0.049 \\
\hline & $\leq 1000$ & $13 / 58$ & 22.4 & \\
\hline \multirow[t]{2}{*}{ Tumor size } & $>3 \mathrm{~cm}$ & $5 / 14$ & 35.7 & 0.33 \\
\hline & $\leq 3 \mathrm{~cm}$ & $11 / 48$ & 22.9 & \\
\hline \multirow[t]{2}{*}{ Nodule } & Multifocal & $6 / 33$ & 18.2 & 0.4 \\
\hline & Unifocal & $10 / 29$ & 34.5 & \\
\hline \multirow[t]{2}{*}{ Distribution } & Bilobar & $8 / 23$ & 34.8 & 0.41 \\
\hline & Unilobar & $8 / 39$ & 20.5 & \\
\hline \multirow[t]{2}{*}{ Pathological Milan Criteria } & Beyond & $9 / 18$ & 50 & 0.032 \\
\hline & Within & $7 / 44$ & 15.9 & \\
\hline \multirow[t]{2}{*}{ Pretransplant ablative therapy } & Yes & $7 / 22$ & 31.8 & 0.42 \\
\hline & No & $9 / 40$ & 22.5 & \\
\hline \multirow{2}{*}{$\begin{array}{l}\text { Waiting time from diagnosis } \\
\text { until transplant }(\mathrm{m})\end{array}$} & $>3$ & $7 / 38$ & 18.4 & 0.94 \\
\hline & $\leq 3$ & $9 / 24$ & 37.5 & \\
\hline \multirow[t]{2}{*}{ GRWR } & $<1$ & $7 / 19$ & 36.8 & 0.18 \\
\hline & $\geq 1$ & $9 / 43$ & 20.9 & \\
\hline \multirow[t]{2}{*}{ CIT (h) } & $>1$ & $10 / 25$ & 40 & 0.036 \\
\hline & $\leq 1$ & $6 / 37$ & 16.2 & \\
\hline \multirow[t]{2}{*}{ WIT (h) } & $>1$ & $3 / 14$ & 21.4 & 0.7 \\
\hline & $\leq 1$ & $13 / 48$ & 27.1 & \\
\hline \multirow[t]{2}{*}{ Total operative time $(\mathrm{h})$} & $>15$ & $8 / 31$ & 25.8 & 1.0 \\
\hline & $\leq 15$ & $8 / 31$ & 25.8 & \\
\hline \multirow[t]{2}{*}{ Blood transfusion (unit) } & $>10$ & $5 / 10$ & 50 & 0.048 \\
\hline & $\leq 10$ & $11 / 51$ & 21.6 & \\
\hline \multirow[t]{2}{*}{ Tumor grade } & I, II & $8 / 20$ & 40 & 0.39 \\
\hline & III, IV & $7 / 38$ & 18.4 & \\
\hline \multirow[t]{2}{*}{ Differentiation } & Well & $2 / 18$ & 11.1 & 0.049 \\
\hline & Moderate/poor & $14 / 40$ & 35 & \\
\hline \multirow[t]{2}{*}{ Microvascular invasion } & Yes & $6 / 10$ & 60 & 0.048 \\
\hline & No & $10 / 52$ & 19.2 & \\
\hline \multirow[t]{2}{*}{ CNI immunosuppressant } & Yes & $12 / 42$ & 28.6 & 1.0 \\
\hline & No & $4 / 20$ & 20 & \\
\hline \multirow{2}{*}{$\begin{array}{l}\text { Post operative biliary and vascular } \\
\text { complications }\end{array}$} & Yes & $10 / 25$ & 40 & 0.025 \\
\hline & No & $6 / 37$ & 16.2 & \\
\hline \multirow[t]{2}{*}{ Rejection } & Yes & $6 / 14$ & 42.9 & 0.098 \\
\hline & No & $10 / 48$ & 20.3 & \\
\hline \multirow[t]{2}{*}{ HCC recurrence } & Yes & $5 / 7$ & 71.4 & 0.01 \\
\hline & No & $11 / 55$ & 20 & \\
\hline
\end{tabular}

Statistically significant values are shown in italic

$H C C$ hepatocellular carcinoma, MELD model of end-stage liver disease, AFP alfa-fetoprotein, $n g$ nanogram, $m L$ milli Leter, GRWR graft recipient weight ratio, HCC hepatocellular carcinoma, CIT cold ischemia time, WIT warm ischemia time, Calcineurin inhibitor, $h$ hour 
(SRTR) database, suggested that a total tumor volume cutoff at $114 \mathrm{~cm}^{3}$ could discriminate between patients with acceptable outcome and those with poor outcome [6].

Concerning preoperative AFP, Vibert et al. showed that there is no agreement on the cutoff values to consider, which ranged from 200 to $1000 \mathrm{ng} / \mathrm{ml}$. In their studies, $\alpha$-fetoprotein concentration lower than $400 \mathrm{ng} / \mathrm{ml}$ has been used in selecting patients for LT [8].

As regards the microscopic picture of the tumor, our cases with microvascular invasion had high early mortality, and also, Shirabe et al. stated that microvascular invasion, which is identified only by microscopic observation, is associated with poorer outcome or increased recurrence rates after LT [9].

There is debate about how to adjust the immunosuppressant in HCC patients after LT. Baksh et al. reported that tacrolimus was found to promote cell cycle progression and, thus, was linked to increased tumor recurrence as noticed in our study. Also Vivarelli et al., showed that cyclosporine actually induced invasiveness in cells $[10,11]$.

The protocol for follow-up of the graft after transplant is different between centers. Schwartz et al. showed that there is no well-established schedule for follow-up of HCC patients after transplantation. A limitation for the use of routine imaging examination (CT or magnetic resonance imaging) is the high cost- or poor cost-effectiveness to detect HCC recurrence [12].

Our results concerning tumor recurrence matched with what was reported by Hollebecque et al., where HCC recurrence occurred in $8-20 \%$ of recipients. HCC recurrence is usually seen within the first 2 years after LT [13].

Concerning site of recurrence, Schlitt et al. also reported that while recurrence of HCC may present in the transplanted liver, the majority of recurrences are extra hepatic: $53 \%$ of patients present with extra hepatic sites only, $31 \%$ with both extra and intra hepatic tumor, and only $16 \%$ with the liver as the sole site. Extra hepatic tumor presents most commonly in the lungs (43\%) and bones (33\%) [14].

Sotiropoulos et al., in their univariate analysis of recurrence, it was significant with AFP, tumor number, tumor size, bilobar distribution, microvascular invasion, tumor differentiation, the Milan criteria, the UCSF criteria, and multivariate analysis of recurrence was significant with AFP, cumulative size of all HCC, microvascular invasion, and tumor differentiation only. So it includes the positive risk factors in our study [15]. On the other hand, advanced tumor stages, and particularly vascular invasion, are poor prognostic indicators for tumor recurrence in other studies [16].

In a study by Morris-Stiff et al., demonstrated that LT for HCC carried a 1-, 3- and 5-year total survival of 80, 70 and $62 \%$, respectively [17], while 1- and 5-year tumor-free survival was 81, and $64 \%$, respectively, in the study by Kondili et al., [18]. Also in Kornberg et al. study, 5 years total survival of their HCC patients was $74.4 \%$, and the 5 years disease free survival was $65.2 \%$ [19]. This survival is comparable to survival of our study.
$\mathrm{Li}$ et al. reported that in univariate analysis, the number of tumors, total tumor size, lobar distribution, differentiation, macrovascular invasion, microvascular invasion, capsulation of the tumor, and lymph node metastasis were found to be associated significantly with actuarial and tumor-free survival. By means of using the multivariate analysis, total tumor size and macrovascular invasion were found to be independent predictors of actuarial and tumor-free survival [20]. Other study demonstrated that early stage, preoperative chemoembolization, and adjuvant chemotherapy are independent predictors for survival after LT in HCC patients with concomitant $\mathrm{HCV}$ infection. So we had other variables in our results than previous studies [16].

\section{Conclusions}

Selection criteria beyond Milan and beyond UCSF, microvascular invasion, and HCC recurrence are risk factors for poor survival in the multivariate analysis. Expansion of selection criteria beyond Milan and UCSF has no increased risk effect on the recurrence of HCC ( $p$ value $=0.33$ ), but less survival rate than patients within the Milan and UCSF criteria ( $p$ value $=0.02$ ). High serum AFP level if $>1000 \mathrm{ng} / \mathrm{ml}$, tumor grading, and microvascular invasion are risk factors for tumor recurrence in univariate analysis, but only microvascular invasion was an independent risk factor for recurrence of HCC in multivariate analysis. So, all these factors should be taken into account in preparing patients with $\mathrm{HCC}$ for transplant and during postoperative follow-up to achieve better outcomes.

\section{Compliance with Ethical Standards}

Financial Support None.

Conflict of Interest The authors declare that they have no conflict of interest.

\section{References}

1. Mejia A, Nazario H, Mantry P (2012) Liver transplantation for hepatocellular carcinoma. In: Abd Eldayem H, Allam N (eds) Liver transplantation-basic issues, vol 13, 1st edn. Intech, Croatia, pp 277-302

2. Abd Eldayem H (2014) Hepatocellular carcinoma. In: Abd Eldayem H (ed) Hepato-pancreato-biliary surgery, bottom lines, 1st edn. Publishing, Germany, 8: p 79-96

3. Chan C (2013) Liver transplantation for hepatocellular carcinoma. Liver Cancer 2:338-344

4. Mazzaferro V, Regalia E, Doci R, Andreola S, Pulvirenti A, Bozzetti $F$ et al (1996) Liver transplantation for the treatment of small hepatocellular carcinomas in patients with cirrhosis. N Engl J Med 334(11):693-699 
5. Yao FY, Ferrell L, Bass NM, Watson JJ, Bacchetti P, Venook A et al (2001) Liver transplantation for hepatocellular carcinoma: expansion of the tumor size limits does not adversely impact survival. Hepatology 33:1394-1403

6. Toso C, Asthana S, Bigam DL, Shapiro AM, Kneteman NM (2009) Reassessing selection criteria prior to liver transplantation for hepatocellular carcinoma utilizing the Scientific Registry of Transplant Recipients database. Hepatology 49(3):832-838

7. Huo T, Hsu C, Huang Y, Su C, Lin H, Lee R et al (2010) Prognostic prediction across a gradient of total tumor volume in patients with hepatocellular carcinoma undergoing locoregional therapy. BMC Gastroentrol 10:146

8. Vibert E, Azoulay D, Hoti E, Lacopinelli S, Samuel D, Salloum C et al (2010) Progression of alphafetoprotein before liver transplantation for hepatocellular carcinoma in cirrhotic patients: a critical factor. Am J Transplant 10:129-137

9. Shirabe K, Itoh S, Yoshizumi T, Soejima Y, Taketomi A, Aishima S et al (2007) The predictors of microvascular invasion in candidates for liver transplantation with hepatocellular carcinoma-with special reference to the serum levels of des-gamma-carboxy prothrombin. $\mathrm{J}$ Surg Oncol 95:235-240

10. Baksh S, DeCaprio J, Burakoff S (2000) Calcineurin regulation of the mammalian G0/G1 checkpoint element, cyclin dependent kinase 4. Oncogene 19:2820-2827

11. Vivarelli M, Cucchetti A, Piscaglia F, La Barba G, Bolondi L, Cavallari A et al (2005) Analysis of risk factors for tumor recurrence after liver transplantation for hepatocellular carcinoma: key role of immunosuppression. Liver Transpl 11(5):497-503

12. Schwartz M, Roayaie S, Llovet J (2005) How should patients with hepatocellular carcinoma recurrence after liver transplantation be treated? J Hepatol 43(4):584-589
13. Hollebecque A, Decaens T, Boleslawski E, Mathurin P, Duvoux C, Pruvot FR et al (2009) Natural history and therapeutic management of recurrent hepatocellular carcinoma after liver transplantation. Gastroenterol Clin Biol 33(5):361-369

14. Schlitt HJ, Neipp M, Weimann A, Oldhafer KJ, Schmoll E, Boeker $\mathrm{K}$ et al (1999) Recurrence patterns of hepatocellular and fibrolamellar carcinoma after liver transplantation. J Clin Oncol 17(1):324-331

15. Sotiropoulos GC, Lang H, Nadalin S, Neuhäuser M, Molmenti EP, Baba HA et al (2007) Liver transplantation for hepatocellular carcinoma: University Hospital Essen experience and metaanalysis of prognostic factors. J Am Coll Surg 205(5):661-675

16. Shimoda M, Ghobrial R, Carmody I, Anselmo D, Farmer D, Yersiz $\mathrm{H}$ et al (2004) Predictors of survival after liver transplantation for hepatocellular carcinoma associated with hepatitis C. Liver Transpl 10(12):1478-1486

17. Morris-Stiff G, Gomez D, de Liguori Carino N, Prasad KR (2009) Surgical management of hepatocellular carcinoma: is the jury still out? Surg Oncol 18(4):298-321

18. Kondili LA, Lala A, Gunson B, Hubscher S, Olliff S, Elias E et al (2007) Primary hepatocellular cancer in the explanted liver: outcome of transplantation and risk factors for HCC recurrence. Eur J Surg Oncol 33:868-873

19. Kornberg A, Küpper B, Tannapfel A, Katenkamp K, Thrum K, Habrecht $\mathrm{O}$ et al (2010) Long-term survival after recurrent hepatocellular carcinoma in liver transplant patients: clinical patterns and outcome variables. Eur J Surg Oncol 36:275-280

20. Li J, Yan L, Yang J, Chen Z, Li B, Zeng Y et al (2009) Indicators of prognosis after liver transplantation in Chinese hepatocellular carcinoma patients. World J Gastroenterol 15(33):4170-4176 